\title{
REPARO À ORIGEM (INSERTIO SCAPULARIS) DO M. TERES MINOR NO CÃO DOMÉSTICO (*)
}

(REPAIR TO TIIT INSFRIION OH THF TERES MINOR MUSCTA IN THE NOMESTIC DOG)

\section{Orlando M. Paiva}

Assistentio

(1 figur'x)

No decurso dos trabalhos de dissecção realizados a título de liçóes práticas no Departamento de Anatomia da Faculdade de Medicina Veterinária da Lniversidade de São Paulo tivemos, repetidas vêzes, oportunidade de verificar, em membros torácicos de Comis familiaris, a maneira de origem do $M$. teres minor. As peças preparadas apresentavam-se com aspecto sempre uniforme em relação d̀ inserçáo escapular, embora em flagrante desacórdo com as descriçōes registradas em diversos tratados de anatomia comparativa. Por outro lado, a consulta clêstes deixava amplamente patenteada a divergência de opiniño de vários AA., quando se buscava esclarecer a exata origem do citado músculo. Como qualquer dos fatos apontados, isoladamente, seria motivo bastante a suscitar pesquisa sistemática. decidimos reunir material quantitativa e qualitativamente adequado para apreciaçâo e julgamento devidos da questão.

0 interêsse das primeiras observações fixou-se, simplesmente. no comportamento do $M$. teres minor no cão, por isso, também o seu relato se fará em primeiro lugar, nesta nota. Posteriormente, resolvemos estender aos mais mamíferos domésticos, que constituem objeto de estudo das anatomias comparativas e à guisa de revisão, idêntico reparo. A coleta dêste último material, mais demorada, prossegue ainda e os resultados do exame serão divulgados a seu tempo.

Em se tratando de reparo a inserção indicacla de maneira insuficientemente explicita on incorretamente difundida pelos tratados. esperávamos ancontrar, na pesquisa bibliográfica procedida, dados respeitantes à verdadcira inserção escapular do $M$. teres minor, ainda que assinalados sob o título de variedade ou de anomalia. A previsão não se confírmical, pelo menos, em meio d̀ escassa casuística sôbre variedades musculares nos animais domésticos (GRAU), na literatura

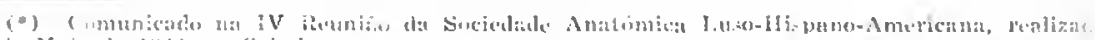

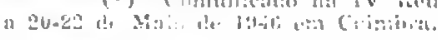


a nosso dispor. Devendo, portanto, cingir-nos aos tratadistas e passando a relatar suas descrições, faremos notar prèviamente que a maioria das anatomias a referir, dada a extensão da matéria e o número de espécies animais a considerar, tomam uma destas para padrão - de hábito à equina - e depois de estudá-láa ampla e minuciosamente, apontam de modo suscinto, sob a epígrafe diferencas, os mais notórịos aspectos anatômicos das restantes espécies em relação a tomada como tipo (lesire, JrRuni in ZIMMerl, VAraid) in BossiCaradonna, Mongtardino e González y Garcia - Álvarez).

Outros tratados em que pese a adoção do mesmo critério, fundamentalmente seguido pelos primeiros, atribuem a cada espécie capítulos separados e subsequentes (Ellenberger-Batm, Sisson e Sisson-Grossman) ou mesmo dedicam-lhe tomos isolados (MARTin).

Por fim, resta-nos fazer notar que ELLENBERger-Baun e Martin resumem em suas obras, a anatomia do cão e gato, conjuntamente, sob a denominação comum de carnívoros.

Estas consideraçōes preliminares não servem, como sc poderia imaginar, de preâmbulo à discussão dos critérios de estudo empregados pelos diferentes AA., que outro é nosso propósito. Elas pretendem antes cxplicar, embora não justifiquem, as múltiplas referências incompletas, omissas e até inexatas e risam, sobretudo, csclarecer porque não dispensamos a descrição do $M$. tores minor no animal tipo, já que em suas linhas gerais deveremos aceitá-lu para o animal em estudo, quando entre as difcrenças não se façam ressalvas ou se kestaquem disposiçoes particulares.

A obscrvação antcrior não se aplica, evidentemente, aos tratados de BRADLEY e BaUm-ZIETZSCHMaNn posto que são anatomias cspeciais do cão.

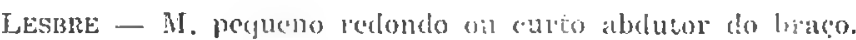

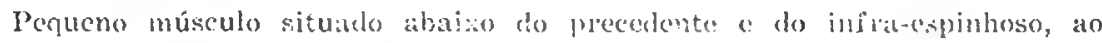
longo da botrat posterior do omoplata, prismátice 16 sua metade inferior onde seus jeixes carmosos sảo cortados jor irterseçós fibrosas, achatado e inteiramente tendinoso na sua metale superior, "ue se divide em linguctas tanto mais longas

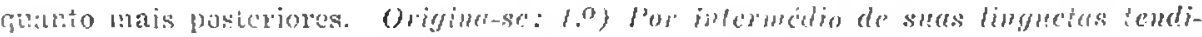

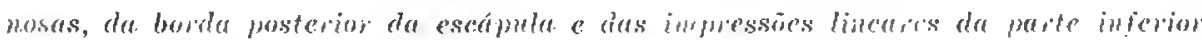

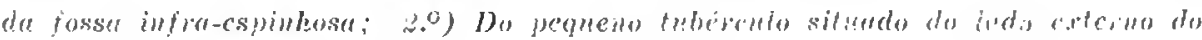

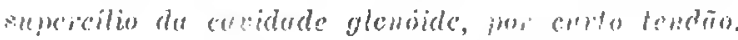

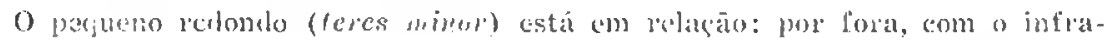
épinhasso e o de!tóde; por deretro, com a longo ancôneo, ancóneo cexterno e a

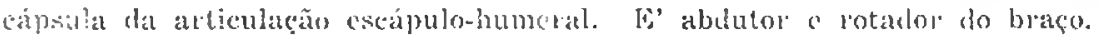

Diferençes: Mão sào assinaladas no căo.

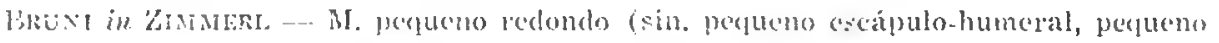
flexol do haco, flexor lateral do braçs). 
E parte destacada alo m. infra-espinhoso. Pequeno, wase com feises ten-

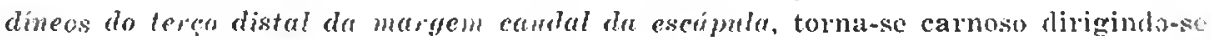
para baixo e clanialmente a se insere com feixes carnosos e tendineos na crista subtroncanteriana.

Difereacres: nos carnivoros é curto e delgado.

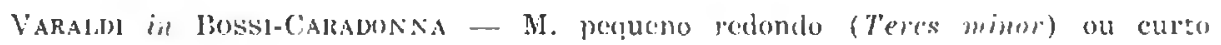
abelutor do braço.

É pequeno, situado entre o infra-espinhoso e o grande extensor do antebraço, tenclíneo na origèn, quase totalmonte carnoso na terminação e estendido ao longo da mararem caudal da escápula até ao húmero.

Começ por meio de numerosos pequenos tendoes, que se inserem sobre "

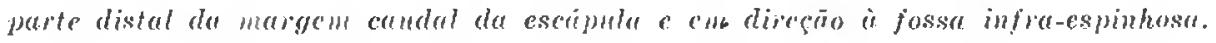
Estes tendóes se dirigem sobre ventre muscular de início pequeno, que depois se vai engrossando, o $\mathrm{cm}$ seguida se achata e se enriquece de feixes tendíneos. Termina sôbre o húmero inserindo-se na crista subtronuiteriana. Sua inserção no húmero é coberta pela fascia omo-braguial e situada entre a inserção do tendão

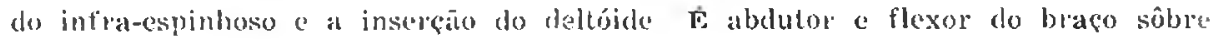
à espádua.

Difereners: é curto a delgado nos calnivoros.

hosciardino - M. curto abdutcr do braço (m. nequeno esćápulo humeral).

Situarlo para trás a ao nivel cla margem posterior da escápula, sob o longo abdutor "o retro-espinhoso. Ti, sua origem, por meio de feires tendincos

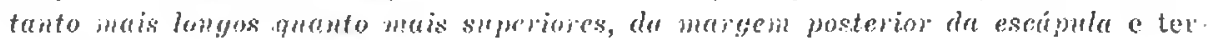
mina :ôbre a crista subtrocantcriana. E congênere do longo alblutor.

Difcremere: não são reforidas no cão.

Goñalez Y Giarcía Álinez - M. curto abolutor do braço (m. perfueno escápulo trocantéricos).

É um músculo longo, prismático, carnoso em seu terço inferior, tendinoso e achatarlo no superior, e, portanto, de estrutura complexa, gue seŗue a direção da borda posterior da escápula.

Situado debaixo do longo abdutur do braco e do sub-expinhoso, mor sula face iaterna relaciona-se com o grosso e curto extensores do antubraço e ligamento da articulação escípulo-humeral.

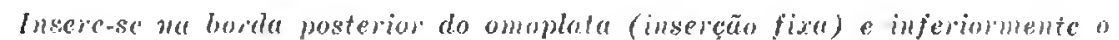

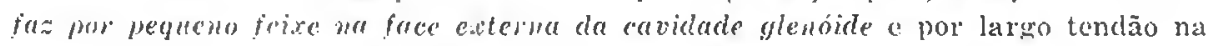
base do trocanter do humero e detrźs do sítio donde o faz o m. deltóide (longo abdutor do braço).

Diferebects: não sio mencionatlas no cão.

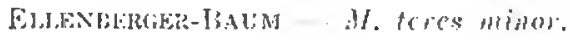

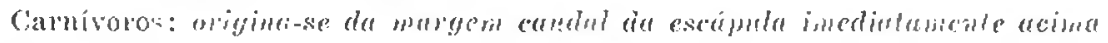
de curidude glenóde (un Tuberosites infreglemidulis) e termina proximalmente

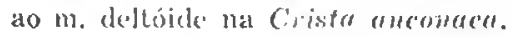

MARTIN - M. Teress mimor.

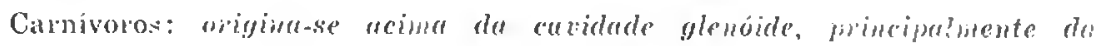
Tubresitas infragloroidalis e termina na Crista hameri. 
Rev. Fac. Med. Vet. S. Paulo - Vol. 3, fasc. 3, 1946

Sisson e Sisson-Grossman - M. pequeno redondo.

No cão: é curto e fusiforme; originc-se em um tubérculo que existe na borda posterior dia escripula, imediatumente acima da cavidade glenóide, e se insere em tubérculo existente na parte superior da crista deltoidéia.

BAUM-ZIETZSCHMANN - . . V leies mimor.

No cão: pequeno e arredondado, está situado na parte distal da margem caudal da escápula e do .II. infraspinatus coberto por êste e pelo $M$. deltoiderts, na face flexoria da articulação escápulo humeral. Origina-se iom unu abnuevrose, fortemente apoiala an Camut longum do M. triceps, do terso distal da wargem caudal do omoplata, mincipalmente, porém, da Tuberositas infraglenoidalis. Termina com curto mas forte tendão em particular saliência da liner ancunaca acinıa do $M$. deltoideus. espêlho.

Sobrepōe-se-lhe de ambos os lados, proximalmente, fraco tendāo em

BRADLEY - M. feres minor.

No cão: estreito e arredondado, está situado ao longo da borda posteriar do $\mathrm{m}$. infra-espinhoso. Origina-se do tergo distal da borda caudal da escápildo: A inserção se faz na Crista tuberculi majoris entre a inserção do tentão do infraespinhoso e a origem da cabeça lateral do triceps.

Açāo: flexão da articulaçāo escápulo-humeral.

Para finalizar citemos ainda IsE Double que sintetiza, nas seguintes linhas, o seu pensar" sôbre a maneira de inserção do $M$. teres minor: "Ao inverso daquêle do homem o pequeno redondo de nossos animais domésticos é aponeurótico na sua extremidade interna, dividida $\mathrm{cm}$ linguetas tendinosas que se insinuam sob o infra-espinhoso para se inserir na borda posterior da escapula o do fossa infraespinhosa e carnoso na sua extremidarle externa inserida no húmero abaixo do troquiter".

Resumindo, podemos reunir nos quatro grupos seguintes, as opiniōes a propósito da origem do $M$. teres minor:

a) da margem caudal da escápula (LESBRE, Mongiardino, Gonzallez y Garcia-Álvarez, Le Double) e das impressōes lineares da parte inferior da fossa infra-espinhosa (Lesbre, Le Double);

b) da parte distal da margem caudal da escápula (VARALd in BOSSI-CARADONNA) ;

c) do terço distal da margem caudal da escápula (BRUNI in ZIMMERL, BAUM-ZIETZSCHMANN, BRADLEY) ;

d) acima da cavidade glenoide, da Tuberositas infraglenoidulis (Fllenberger-Baum, Martin, Sisson, Sisson-Grossman).

Em princípio, talvez pudéssemos invocar, pelo menos, duas razōes motivantes da diversidade dos conceitos exarados: 1) a existência de real e sensível variabilidade na extensão insercional escapular do $M$. teres minor; 2) a possível influência, nas apreciações, acarretada pela natureza do material selecionado para exame e veiculando-se através fatores tais como idade, sexo, raça e tipos morfológicos. Adiantaremos desde já, que nenhuma delas se comprovou. 


\section{MATERIAL E METODO}

As observações di presente nota baseiam-se no estudo de 101 membios torácicos de cães enviados ao Departamento de Anatomia para trabalhos de dissecção; excetuando-se um feto, os restantes animais procederam do Depósito da Prefeitura Municipal, constituindo lote extremamente variado e por isso mesmo, apropriado para 0 gênero de traballho em objetivo.

Das 101 peças preparadas, 92 correspondem à dissecção dos membros torácicos direito e esquerdo de 46 cães, de idade e talhe extremamente diversos, compreendendo 24 machos, 7 fêmeas e 15 pares pertencentes a animais cujo sexo não pôde ser determinado; 9 membros isolados ( 5 l). e 4 E.) nas mesmas condições dêstes últimos, completam o material estudado.

Salvo algumas dissecęões praticadas a fresco, a maioria foi realizada em peças fixadas pelo formol, seguindo-se ao abordar o $M$. teres minor, at habitual técnica de rotina para dissecção dos $\mathrm{mm}$. escapulares. Bem a propósito cabe referir que, para isolar a lâmina aponeurótica do $M$. teres minor dos MM. infraspinatus e Caput longum do $M$. triceps, forte e respectivamente aplicados às faces lateral e medial da mesma, deve-se proceder cautelosamente afim de manter integras as delicadas linguetas tendíneas da citada lâmina.

Quando esta precaução é devidamente estimada obtem-se peças nas quais o simples exane macroscópico, com ou mesmo sem auxílio de lupa, permite acompanhar o trajeto das fibras tendíneas desde o ponto de onde se destacam da porção muscular até à inserção sôbre a escápula. Entretanto, para melhor documentar a conexão entre fioras musculares c tendíneas, houvemos por útil praticar corces histológicos frontais do $M$. teres minor, na zona de transição entre pars musculuris e parw aponeurotica. Para êsse fim utilizamos 6 peças convenientemente retiradas e, após fixação em líquido de Bouin, coradas pela hematoxilina-eosina e pelos métodos de Van Gieson e Mallory.

\section{OISSERVACOOES PESSOAIS}

Fundam-se no material discriminado e correspondem à clescrição tão completa quanto possível do $M$. teres minov no cão doméstico. Considerando çue diferenças atinentes a idade, sexo, raça (investigadas em mestiços) e tipos morfológicos não foram por nós anotadas, tal descrição sc ajusta ou serve de base, em seus traços gerais, a todos os exemplares jecolhidos. 
O M. teres minor do cão (fig. 1), disposto ao longo da margem caudal da escápula, compõe-se de duas partes perfeitamente delimitáveis: 1) pars muscularis; 2) pars aponeurotica.

A pars muscularis, assemelha-se a pirâmide triangular, ocupa o terço distal da margem costal da escápula, situando-se caudo e algo lateralmente à articulação escápulo-humeral. Nela distinguem-se três faces de extensões clesiguais, nitidamente demarcadas por outras tantas arestas ou margens.

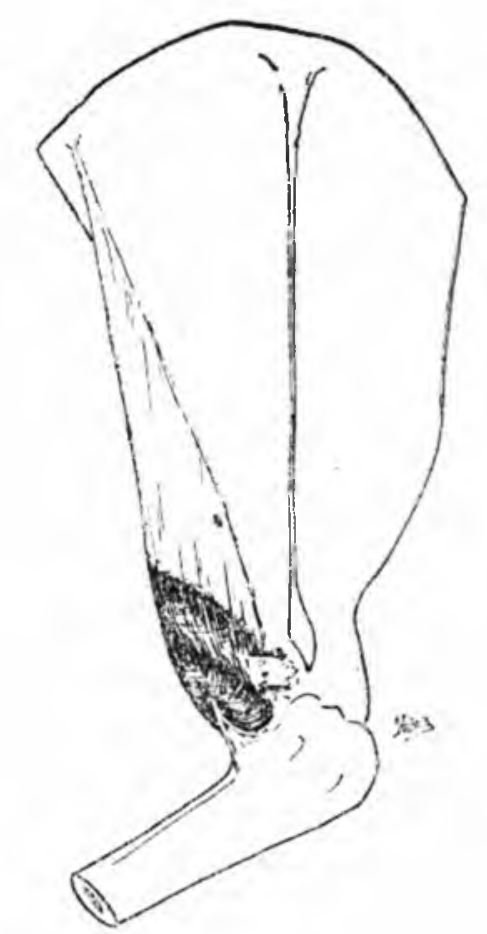

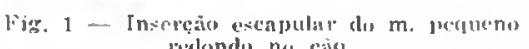

As faces maiores têm areas aproximadamente equivalentes e são recoberias por finas lâminas aponeuróticas, que emprestam a parte de suas superficies carateristica aparência brilhante; orientam-se nos sentidos crânio-lateral e caudo-medial e relacionam-se, respectivamente, com M. infraspinatus e o C'aput longum e Caput laterale do $M$. triceps brachii: a face crânio-lateral apresenta-se plana, a caudomedial bombeada. 
A face menor, voltada em direção caudo-lateral e subjacente à pars ucromialis do $M$. deltoideus, mostra-se penetrada a partir da base por tendão à maneira de cunha.

As margens caudal e lateral, vizinhas e ligeiramente arqueadas, limitam a face menor, convergem proximalmente e unem-se antes de atingirem a parte apical da porção muscular. A margem cranial, partindo do ponto onde se tocam as margens caudal e lateral, forma no início, acentuada curvatura de concavidade ventral, constituindo neste primeiro tracto a jå designada jarte apical da porção muscular; a seguir inclina-se suavemente em direção ao colo escapular, ao nível do qual termina.

A parte basilar, talhada muito obliquamente no sentido médiolátero-distal, mostra-se quadrangular pelo aparente e brusco achatamento do músculo abaixo da margem cranial ao se apoiar à articulaçào escápulo-humeral; a parte basilar assenta ademais sôbre o Caput laterale do $M$. tricepss brachii.

A pars cponeurotica representa os $2 / 3$ proximais do $M$. teres minor, e laminar, irregularmente triangular e finamente estriada oferecendo a estudio duas faces e três bordas.

1) A face lateral, unida sòlidamente ao $M$. infruspinatus, forma superfície comum com a facc crânio-lateral da porção muscular.

2) A face medial, intimamente aderente ao Caput longum do M. triceps brachii, continua-se pela face caudo-medial da porção muscular.

A borda cranial - interrompida no limite dos terços médio e distal, afim de permitir a passagem a formações vásculo-nervosas e por meio da qual se faz a inserção escapular - e a borda caudal - que se estende desde o ponto de contacto das bordas lateral e caudal da porção muscular até o ângulo dorsal da es:cápula - se intersecam à altura clêsse mesmo ângulo assinallando o limite mais proximal da inserçāo aponeurótica.

P'urs aponeuroticu e prers muscularis estão em continuidade ao longro das margens ventral da primeira e cranial da segunda, através bem marcada linha curva cuja trajetória já delineamos.

A origem (insertio sc(t)uluris) faz-se: 1) por intermédio da margem cranial da pars aponenrotica, mediante finas linguetas tendineas, tanto mais longas quanto mais caudais, da margem caudal escapular, desde o ângulo costal até cêrca do colo da escápula. A linha da inserção do $M$. teres minor costal, desvia-se dia margem propriamente dita, reservada ao $\mathrm{m}$. grande redondo, para prosseguir cranial e paralelamente à margem. 
A exceção dos feixes tendíneos originados abaixo do ponto por onde transitam os mencionados elementos vásculo-nervosos, pouco numerosos, mais esparsos e ligeiramente arciformes, os restantes são paralelos e muito unidos. 2) graças a curto e largo tendão que, partindo da porção basilar, vai ao supercílio da cavidade glenoide, particularmente à Tuberositas infraglenoidalis.

A inserção (insertio humeralis) dá-se na Crista tuberculi majoris entre a inserção do $M$. infraspinatus e a origem do $M$. triceps brachii (Caput laterale), por meio do tendão assinalado na face menor da parte muscular e de regular número de fibras musculares.

\section{CONSIDERAÇÕES GERAIS}

De início aludiremos à nomenclatura empregada para designar o músculo em estudo. Os termos $M$. marginalis scamulae (minor) $M$. infra-scapularis minor, M. obliquus scapulae (minor) propostos por FroHSE e FränKeL para substituir, na espécie humana, o pouco sugestivo mas muito arraigado nome pequeno redondo, indicariam também mais significativamente o $M$. teres minor do cão. Denominações outras derivadas, como as que alvitram os AA. citados, quer das inserções, da direção ou, por último, da ação do músculo, seriam não só aceitáveis mas até preferiveis à determinada pela B. N. A.

Limitando esta contribuição, como foi nosso intento, ao estudo da origem do $M$. teres minor, nem por isso nos desobrigariamos de registrar quaisquer variedades e anomalias, tais como maior ou menor extensão na origem escapular, ausência, fusão, divisão em feixes e correlativa individualização do $M$. teres minimus de Grubre (in TESTUT) si porventura com elas tivéssemos deparado ao examinar o pequeno redondo.

A propósito da individualidade dêste músculo, todavia, abstendo-nos de comentar, de modo mais amplo, por muito vaga, a asserção de MaCalister (in LE Double) quando escreve: "o teres minor falta como músculo próprio nos Cetáceos, Roedores, Marsupiais e maior parte dos Carnivoros", aproveitamos o ensejo para restringir a inclusão dos Canídeos domésticos no último grupo zoológico, quando a êle se associe o conceito de MACALISTER visto como, sob o aspecto morfológico, o $M$. teres minor sempre foi encontrado qual entidade anatômica independente; ao asseverar êsse fato não menosprezamos certo número de casos nos quais, levando em conta a dificuldade em isolar pars aponeurotica do pequeno redondo e $M$. infraspinatus, ser-nos-ia permitido falar, com algum rigorismo, em fusão parcial. 
Vem a propósito referir a elevada freqüência desta fusão na espécie humana. Estudando algumas variaçōes dos músculos da espádua, BARONI e LANGER apontaram a disposição clássica dos $\mathrm{mm}$. pequeno redondo e infra-espinhoso em 46 casos; nos outros 54 , puderam os AA. verificar fusão mais ou menos intima de ambos.

Mais justificável, talvez, do ponto de vista funcional, a afirmativa de MACALISTER poderia, implícita mas não expressamente, coadunar-se melhor ainda com o estabelecido por GREIG: "Filogenèticamente o Teres minor pertence ao Deltoideus, do qual se separou, como resulta das observaçeõs de numerosos autores".

É ainda GREIG quem faz a apreciação seguinte: o $M$. teres minor mostra-se nas formas pronogradas de constituição mais fraca do que nas formas ortogradas. Nas primeiras, o pêso corpóreo contribuiria poderosa e passivamente para a junção das superfícies articulares da articulação escápulo-humeral, enquanto nas segundas o $M$. teres minor agiria ativamente no sentido de manter aproximadas cabeça humeral e cavidade glenoide. No cão e nos animais domésticos em geral o $M$. teres minor revela-se, com efeito, pouco desenvolvido, fato perfeitamente compreensível a luz da interpretação de GREIG.

Daremos por fim a conhecer o trabalho de TEHVER — sôbre a inervação dos $M m$. supra - e infraspinatus e a publicação de von SÖREN NORÉN - concernente ao comportamento funcional e assimetria da musculatura da extremidade torácica num caso de fratura humeral - pela menção fortuita que ambas fazem ao $M$. teres minor do cão.

TEHVER, em experiências no cão, efetuou a neurectomia do $N$. suprascapularis do lado esquerdo, numa extensão de $2 \mathrm{~mm}$., tendo deixado íntegro o lado direito, para contrôle. Decorrido o tempo estabelecido pelo A. e após sacrifício do animal a pesagem dos $\mathrm{Mm}$. supraspinatus, infraspinatus, deltoideus e teres minor dos lados direito e esquerdo, revelou pronunciada atrofia dos dois primeiros músculos à esquerda, isto é, do lado neurectomizado. Os $M m$. deltoideus e teres minor, dêste mesmo lado, não manifestavam redução de pêso, comparativamente ao lado normal. TEHVER, citando os tratadistas, resume também dados respeitantes à inervação do $M$. teres minor: $N$. suprascapularis (Sch MALTZ), N. axilaris (SIEglbaUer) e simultâneamente $N n$. suprascapularis e axilaris (MARTIN e ELLENBERGER-BAUM ).

Eximimo-nos de discutir as questões relativas à inervação e também à função do músculo teres minor. A primeira foge ao 
designio da publicação; a segunda parece satisfatòriamente esclarecida.

Von Sören Norén através a determinação do pêso dos músculos dos membros torácicos num cão apresentando fratura do húmero do lado direito, já curada, achou em alguns dêles, na extremidade lesada, redução de pêso em proporẹão ao dos músculos homônimos do membro sāo.

O M. teres minor sofreu evidente redução de pêso no membro lesado, embora, talvez, não na mesma medida dos mais, porque êste músculo, afirma von Sören NoRśn, também pode ser, normalmente, algo menor do lado direito, conforme se deduz dos proveitosos resultados obtidos pelo A., mediante confronto do pêso dos músculos em membros torácicos de dois cães normais, com intento de explicar a assimetria normal.

No trabalho dêste último A., destacamos as observaçóes relativas à diminuição de pêso dos músculos situados na extremidade lesada, ou melhor, chamaremos a atenção para a pouco pronunciada atrofia do M. teres minor dêsse lado.

Ao exame dos preparados histológicos, destinados a comprovar a continuidade entre pars aponeurotica e purs muscularis do $\mathrm{m}$. pequeno redondo - fato cabalmente demonstrado. graças a êsse recurso - tivemos ensejo de positivar que, estruturalmente, o $M$. teres minor reflete aspecto condizente com sua importância funcional secundária. Este desempenho funcional discreto dar-nos-ia, com tôda a probabilidade, a razão de ser da interessante observação de von SÖREN NORÉN relativamente ao comportamento lo $\mathrm{m}$. pequeno redondo.

Quanto ì origem do músculo - motivo vrecipuo da presente contribuição - necessário se torna retificá-la, pois, como se declarou de início, os dados vulgarizados pelos tratados de anatomia veterinária e anatomias do cão, nesse pormenor são incompletos, omissos e por vêzes inexatos.

Em relação ao desenvolvimento da porção carnosa dos músculos, Lubosch escreve: "Há formaçōes fibrosas que sob o ponto de vista prospectivo são músculos". Com referência à parte aponeurótica do m. pequeno redondo diríamos: representa, retrospectivamente, formação de carater muscular; em outras palarras, a pars aponeuroticu, corresponderia ao trajeto percorrido pelos feixes musculares ao curso da reducão sofrida pelo músculo nas formas pronogradas. 


\section{RESUMO}

Com o objetivo de estudar a origem (insertio scupularis) do M. teres minor no cão doméstico, o A. dissecou 101 membros torácicos, As peças preparadas apresentavam aspecto sempre uniforme em relaf̧ão à inserção escapular do músculo em observação, embora em flagrante desacordo con as descrições registradas nos diversos tratados de Anatomia Comparativa, nesse particular incompletas, omissas e por vêzes inexatas.

De acôrdo com o A. ar origem faz-se: 1) por intermédio da margem cranial da par's aponeurotica, mediante finas linguetas tendíneas, tantos mais longas quanto mais caudais, da margem caudal escapular, desde o ângulo costal até cerca do colo da escápula. A linha de inserção do $M$. teres minor, próximo ao espessado ângulo costal, desvia-se da margem pròpriamente dita, para prosseguir cranial e paralelamente à mesma margem. 2) graças a curto e largo tendão que, partindo da porção basilar da pars muscularis, vae ao supercílio da cavidade glenóide, particularmente à Tuberositas infraglenoidalis.

O A. critica a nomenclatura empregada para designar o m. jequeno redondo e aprecia a questão da individualidade do mesmo. Aceita e confirma a opinião de GreIg quanto à mais fraca constituição dêste músculo nas formas pronogradas. Com efeito, no cão e nos animais domésticos em geral, o $M$. teres minor revela-se pouco desenvolvido. Cita TFHVER e von Sören NORÉn pela menção fortuita que ambos fazem ao $\mathrm{m}$. pequeno redondo do cão.

Com referência à parte aponevrótica do $M$ teres minor, o A. admite que ela corresponda ao trajeto percorrido pelos feixes musculares ao curso da redução sofrida pelo músculo nas formas pronogradas.

\section{SUMMARY}

The A. dissected 101 thoracic limls with the scope of studying the origin (insertio scapularis) of the teres minor muscle in the domestic dog. The pieces prepared showed aspect always miform concerning the scapular insertion though in flagrant disagrement. with the descriptions reconded in the different treatises of Comparative Anatomy, in this particular incomplete, omissive and sometimes inexact.

According to the A. the teros minor muscle originates: 1) by means of the creniul margin of the pars aponeurotica, through thin tendinons fibers, the longer the move caudal, on the 
caudal border of the scapula, from the costal angle to near the scapular neck. The insertion line of the teres minor muscle, near the thickened costal angle, deviates from the margin properly said muning cranially and parallel to the same margin. 2) by means: of a short and wide tendon that arises on the basilar portion of the pars muscularis and is inserted into the supercil of the glenoid cavity, particularly in the Tuberositas infraglenoidalis.

The A. criticizes the nomenclature employed to name the teres minor muscle and appreciates the question of the individuality of the same. Accepts and confirms the opinion of GREIG dealing with the weaker constitution of this muscle in pronograde forms. In fact, in the dog and in domestic animals generally the teres minor muscle shows little development. Quotes TEHVER and VON SöREN NORÉN on account of the mention both make about the teres minor muscle of the dog.

About the aponeurotic portion of the teres minor muscle, the A. admits that it corresponds to the traject run by the muscular fibers during the reduction suffered by the muscle in pronograde forms.

\section{BIBLIOGRAFIA}

Baroni, B. e LANGer, A. - 1926 - Sopra alcune variazioni della spalla. Monit. Zool. It., 12: 297-304

Baum, H. e ZietzschmanN, O. - 1936 - Handbuch der Anatomie des Hundes. 1. 2 Auf. Berlin, Paul Parey

Bradley, O. Ch. - 1943 - Topographical Anatomy of the dog. 4th. ed. Edinburg, Oliver and Boyd Ltd,

Bruni, A. C. - 1929 - “in" Zimmerl, U. Trattato di Anatomia veterinaria. 1. Milano, Francesco Vallardi

Ellenbercier, W. e BaUm, H. - 1932 - Handbuch der vergleichenden Anatomie der Haustiere. 17 Auf. Berlin, Julius Springer

Frolise, F. e FräNKel, M. - 1908 - "in" K. von Bardeleben Handbuch der Anatomic des Menschen - Dic Muskeln des menschlichen Armes 2: (2):: $54-8$

GONZALLEZ Y GaRCía-ÁLVARE\%, R. G. - 1929 - Anatomia comparada de los animales domesticos. 33. ed. Zaragoza, "La Academica"

GraU, H. - 1932 - Uber einige Muskelvarietäten bei Haustieren, besonderes über Varietäten des "M. extensor hallucis longus" und des "M. tibialis anterior" beim Hunde. Anat. Anz., 74 (11-12): 218-27

GreIG, D. M. - 1923 - On the importance and function of the "teres minor" muscle. Edinburg Med. Journ., 30, 16-\$1, 2 Abb "in" Anat. Bericht. 3, ref. $210: 69,1925$

Le Double, A. F. - 1897 - Traité des variations du système musculaire de l'homme et leur signification au point de vue de l'anthropologie zoologique. 2. Paris, Schleicher frères 
Lesbre, F. X. - 1922 - Précis d'Anatumie comparée des animaux domestiques. 1. Paris, J. B. Baillière et fils

Lubosch, W. - 1937 - Ein Beitrag zur vergleichenden Anatomie des Muskelsystem. Morphol. Jahrb., 80 (1) : 89-178

Martin, P. - 1923 - Lehrbuch der Anatomie der Haustiere. 4. 2 Auf. Sttutgart, Schickhart \& Ebner

Mongiardino, T. - 1903 - Trattato di Anatomia topografica dei mammiferi domestici. Torino, Luigi Delgrosso

Sisson, S. - 1933 - Anatomia de los animales domesticos. Barcelona, Salvat

Sisson, S. e Grossman, J. D. - 1945 - The Anatomy of the domestic animals. 3rd. ed. Philadelphia, W. B. Saunders Company

Tehver, J. - 1928 - Verlauf des "Nervus suprascapularis" und Innervation des "Musculus supra" — und "infraspinatus" bei den Haussäugern. Anat. Anz., 66 (16-18) : 295-9

Testut, L. - 1884 - Les anomalies musculaires chez l'homme expliquées par l'Anatomie comparée (Leur importance en Anthropologie). Paris, G. Masson

VARALDI, L. 1909 - "in" Bossi, Caradonna Trattato di Anatomia veterinaria. 1. Milano, Francesco Vallardi

VON SÖREN NORÉN - 1938 - Die funklionelle Anpassung der Muskulatur nach einer Humerus-fraktur beim Hund nebst Bemerkungen über die Muskelasymmetrie an der vorderen Extremität beim Hunde. Anct. Anz., 87 $(11-13): 228-39$ 